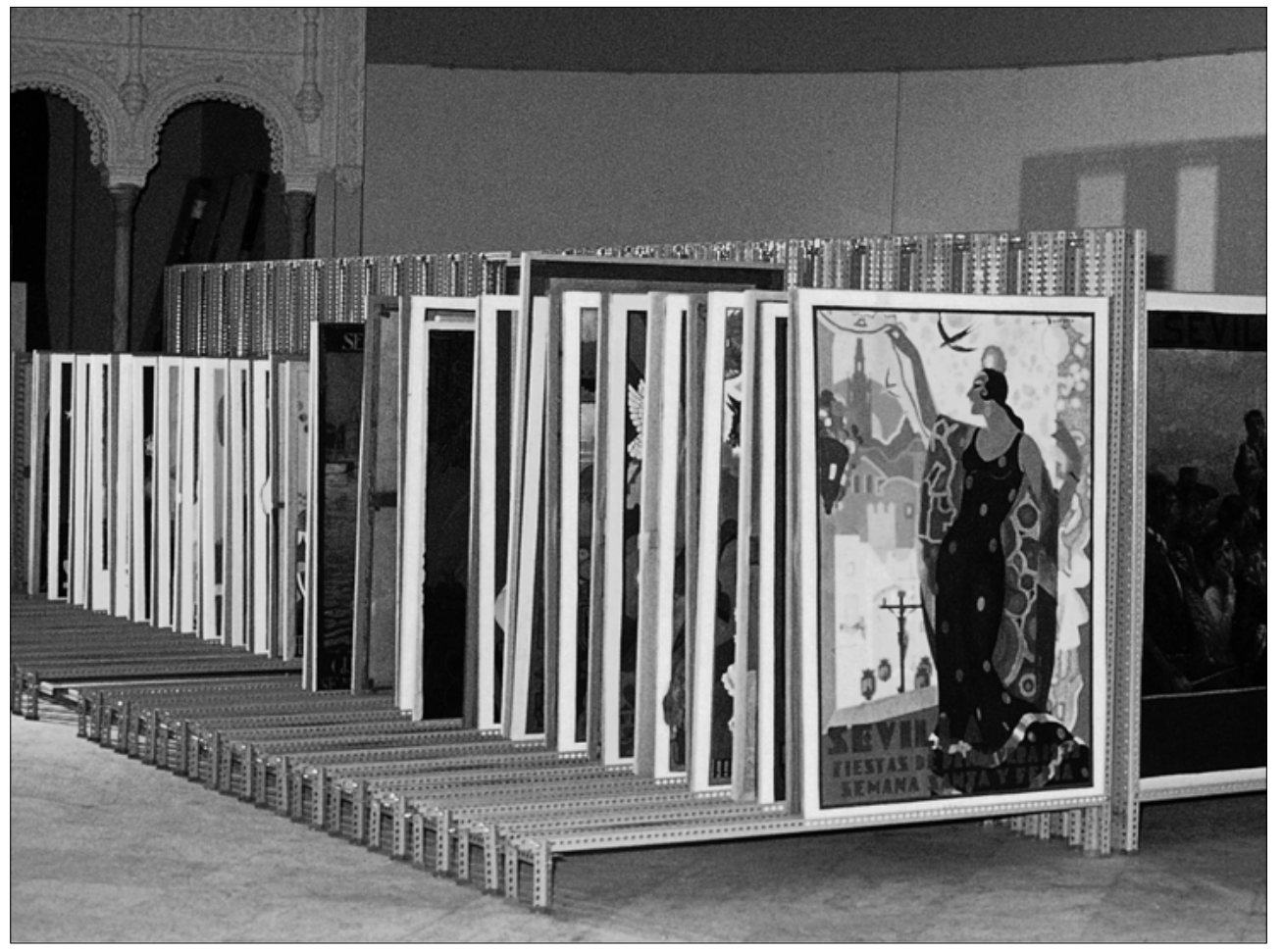

\title{
El Estudio de la Cultura
}

\section{en los Museos Etnográficos}

Esther Fernández de Paz

Universidad de Sevilla
Desde hace ya bastantes años, en algunas ocasiones me he ofrecido a guiar la visita al Museo de Artes y Costumbres Populares de Sevilla a muy diversos colectivos: escolares, ancianos, estudiantes norteamericanos, maestros que debían acompañar después a sus alumnos, e incluso estudiantes de Antropología. En todos los casos, mi mayor interés se centraba en las respuestas que ofrecían a mi interrogante inicial: ¿qué esperais ver? ¿qué pensais que es un museo etnográfico? ¿qué creeis que vais a aprender con la visita?

Obviamente, la contestación variaba dependiendo del grupo en cuestión. Sin embargo, por encima de los matices y del distinto grado de preparación académica, mayoritariamente me topaba con la idea romántica de que el museo servía para conservar y mostrar objetos de nuestro pasado, especialmente aquéllos que la industrialización ha inutilizado. O sea, tal como reza en las puertas del museo: los restos de las costumbres populares. 
Acto seguido osaba indagar cuál sería la respuesta si en lugar de tratarse de un museo etnográfico o de artes y costumbres populares, nos halláramos ante un museo antropológico o etnológico. En esos casos la contestación también era coincidente: entonces, naturalmente, se hallarían ante objetos procedentes de culturas lejanas y primitivas.

En efecto, esa distinción refleja con bastante fidelidad los principios que guiaron la implantación de las primeras colecciones que hoy alimentan los museos etnográficos o antropológicos, sin que, por otro lado, tengan nada en común con los planteamientos teóricos que en la actualidad los presiden. Cambio que, por lo que se ve, ha calado poco en la conciencia de la sociedad.

\section{Orígenes de las colecciones}

Como sabemos, los gabinetes y museos de Historia Natural se convierten, a partir de los trabajos de Darwin, en los lugares más idóneos para acumular los testimonios que permitieran estudiar la evolución biológica de todas las especies, incluida el hombre, a lo que se une la evolución cultural, entendida en esos momentos como los estadios progresivos que desde el "salvajismo" conducen a la "civilización". De ahí las distintas secciones: mineralogía, botánica, zoología, arqueología, pueblos primitivos...

Dicho material, acopiado con los objetos substraídos en las expediciones científicas, incluidas las investigaciones antropológicas, es el que poco a poco se va individualizando en los distintos museos antropológicos.

En realidad, ni los unos ni los otros fueron creados por antropólogos', aunque en algunos casos comenzaron en seguida a trabajar en ellos con el apoyo de los gobiernos coloniales, compaginándolo con sus tareas docentes e investigadoras. Es el caso, por ejemplo, de Pitt-Rivers en Oxford, de Boas en Nueva York o de Mauss en Francia. En España, es el Dr. González Velasco quien en 1875 financia y dirige hasta su muerte el Museo Anatómico, siempre conocido como Museo Antropológico.

En algunos casos concretos, los fondos comienzan a clasificarse atendiendo a los diferentes rasgos culturales o bien a la funcionalidad de los mismos. Sin embargo, en líneas generales, el interés básico de aquellas instituciones se concentraba en los aspectos tecnológicos, base de las etapas evolucionistas, amén de restos de vestimetas y curiosidades artísticas, todo ello ordenado generalmente por áreas geográficas. La intención de plantear la enseñanza global de aquellas culturas es inexistente, y menos aún el establecimiento de comparaciones culturales interétnicas. Eso era labor de la literatura antropológica, donde se pueden expresar conceptos, explicar simbolismos, etc.; al parecer, algo imposible de conseguir a través de las piezas de los museos.
Otro camino para la creación o ampliación de fondos de museos antropológicos fueron las Exposiciones Universales que desde mediados del siglo XIX organizan los nacientes Estados, persiguiendo numerosos intereses. Uno de ellos, la demostración de su poder colonial, se materializaba con la ostentación de productos y enseres traídos desde sus lugares de origen, presentados en decorados reconstruidos en los que, a veces, se incluía la exhibición de los propios indígenas para recrear unas formas de vida exóticas e incuestionablemente atrasadas. Para ello contaban con la inestimable ayuda de algunos antropólogos que, lejos de cuestionarse el servicio que prestaban al colonialismo, volcaban su trabajo en la investigación de estos pueblos y en la recogida de material con el que alimentar los museos donde, a su vez, poder continuar los estudios.

Así se conformaron varios museos europeos y norteamericanos, como el propio Musée du Trocadéro de París, creado con ocasión de la Exposición de 1878, en la que Francia había reconstruido edificios de sus colonias.

España no fue ajena a este afán de exhibición colonial, participando en estas Exposiciones y celebrando, además, muestras monográficas de sus restos imperiales. La de Filipinas, Marianas y Carolinas, celebrada en Madrid en 1887, fue el motor de creación del Museo de Ultramar, cuyos fondos pasarán posteriormente a engrosar los de la sección de Antropología, Etnografía y Prehistoria del Museo de Ciencias Naturales, donde se habían depositado las colecciones del ya desaparecido Museo Antropológico. Allí se aprovechó para estudiar de cerca a los nativos, especialmente desde la óptica de la Antropología Física².

Paralelamente van surgiendo los museos de "lo propio" como consecuencia de múltiples visiones e intereses.

La fuerza de la utilización de los museos como armas propagandísticas es algo que se intuyó claramente en el periodo de asentamiento de los nuevos Estados. Así, con el más claro apoyo oficial van surgiendo museos nacionales como medio de exaltación de las culturas respectivas, en pro de la extensión del sentimiento de identidad nacional. Como ejemplos podrían citarse en Europa el Germanische Museum de Nuremberg ( 1853 ) o en América el Museo Nacional de México, decretado por el primer gobierno constitucional e inaugurado finalmente en I866, germen del actual Museo Nacional de Antropología.

Estamos ante los primeros modelos a seguir en la mayoría de los Estados occidentales, que irán siendo repetidos por muchos de los gobiernos de principios de este siglo.

Del espíritu romántico surgen también en el siglo XIX los primeros museos etnográficos que persiguen no tanto la exaltación política de lo nacional, cuanto mostrar las "bondades del pasado" ante el avance de la industrialización. De ahí la valoración de las formas 
de vida calificadas como populares y tradicionales. Se trata de un canto de alabanza al pasado a través de sus objetos, sin demasiada intencionalidad científica, crítica o analítica. Los primeros se concentran en la Europa del Norte: Nordiska Museet de Estocolmo (1873), Dansk Folkmuseum en Copenhague ( 1879), Norsk Folkmuseum en Oslo (1894), etc. Ta m b i én son éstos los países pioneros en una nueva forma de presentación museológica: los museos al aire libre, creados con reconstrucciones de su arquitectura popular, incluyendo interiores perfectamente equipados para recrear las actividades tradicionales, sea con reproducciones o incluso con sus propias gentes. El primero se fundó en $|89|$ en la colonia de Skansen, en Estocolmo, al que pronto siguen otros como el de Lyngby en Dinamarca (1901) o el de Arnhem en los Países Bajos (1912). La inspiración en las recreaciones experimentadas con motivo de las Exposiciones Universales era evidente.

Pero no todos fueron museos de nueva creación. Dentro de este movimiento, se van añadiendo asimismo secciones de etnografía local en el interior de los museos antropológicos existentes. Así Francia, al tiempo que potencia los museos cantonales, agrega en 1884 una sección de etnología propia en el Musée du Trocadéro, de donde posteriormente se desgajará para constituir el Musée National des Arts et Traditions Populaires.

España, como es de sobra conocido, tampoco permaneció ajena al movimiento folklorista decimonónico, aunque una vez más hemos de constatar los diferentes tratamientos y objetivos que lo guiaron en sus distintas áreas culturales.

Del folklorismo del Norte destaca singularmente la labor de los excursionistas, que logran crear el primer museo folklórico de España, el de Ripoll en 1919:

"Cataluña es para ellos como un gran museo que se debe descubrir e inventariar. Los románticos Iloraban «la perdida grandeza de la patria», ellos recogen la tradición para guardar «en un rincón del corazón» el recuerdo de este mundo moribundo"3.

Por su parte, los folkloristas machadianos buscan también la creación de museos en cada región española, donde testimoniar la cultura y saberes del pueblo, no ya como simple romanticismo ni como alabanza nacionalista sino como "reconstrucción de la historia y cultura nacional", tal como recogen las bases de la Sociedad El Folk-lore Español (I88I). El propio Demófilo intentó a finales de siglo conseguir el apoyo oficial para la apertura en Madrid de un gran museo folklórico de los distintos pueblos de España, sin ningún éxito.

Nos será hasta 1934 cuando se decrete la fundación del Museo del Pueblo Español, de manos de Luis de Hoyos Sáinz ${ }^{4}$ :

"Cumple el Gobierno con la deuda cultural y política contraída por la República con el «Pueblo Español», que no tiene, por excepción única en Europa, Museo adecuado que recoja las obras, actividades y datos del saber, del sentir y el actuar de la masa anónima popular, perdurable y sostenedora, a través del tiempo, de la estirpe y tradición nacionales, en sus variadas manifestaciones regionales y locales en que la raza y el pueblo, como elemento espiritual y físico, han ido formando nuestra personalidad étnica cultural."

Es innegable el salto cualitativo que se trasluce en este párrafo inicial del Decreto Fundacional del Museo, en cuanto a la finalidad del mismo. No se perseguía el simple acopio de materiales como mera añoranza del pasado sino la exposición y estudio del conjunto
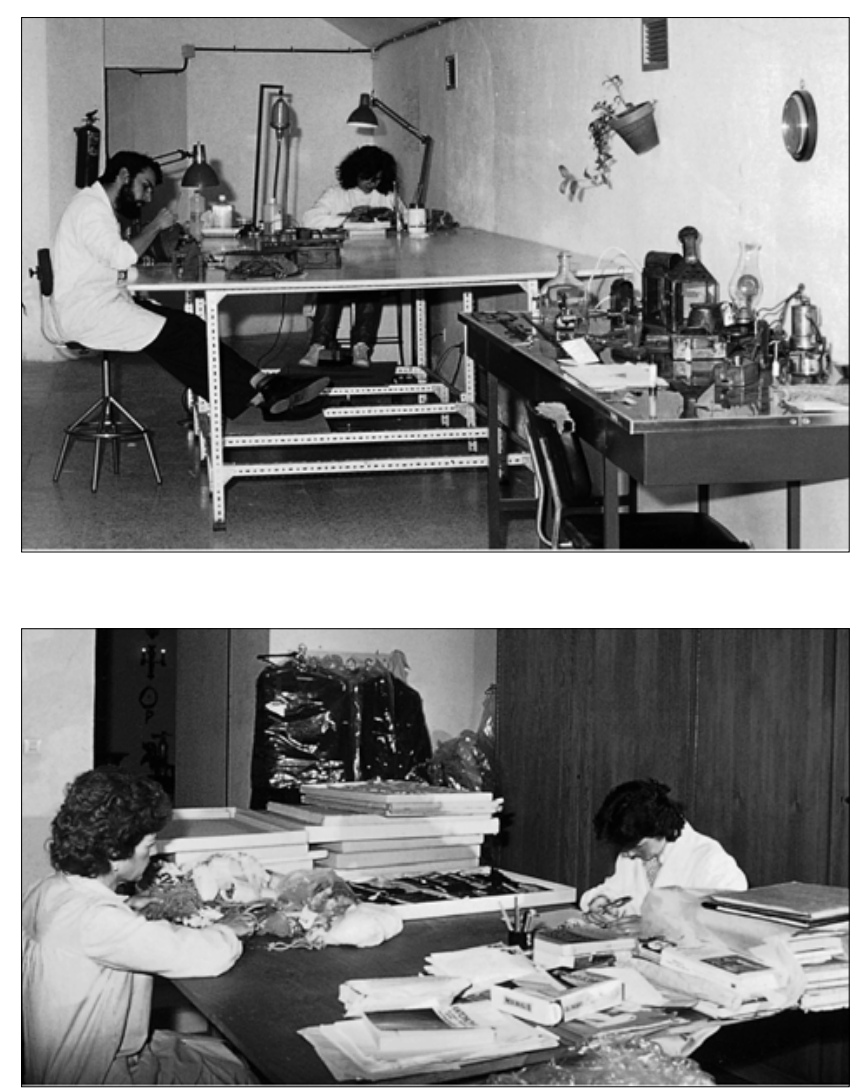

de las manifestaciones culturales, como medio de 2. Taller de restauración 3. Taller de costura ahondar en el conocimiento del presente. Objetivo imposible, por otro lado, si sólo se consideran las clases populares como sectores aislados e incontaminados de la sociedad global.

Nunca sabremos lo que el desarrollo de este museo pudo llegar a suponer en la superación de anquilosados supuestos teóricos, tanto antropológicos como museológicos. La caída del gobierno republicano frustró su apertura al público, lo que no ha impedido, por otro lado, que en su interior se haya trabajado ininterrumpidamenté.

A medida que avanza el siglo $X X$, el interés europeo por los museos de lo propio se acrecienta en detrimento de los que se ocupan de las culturas lejanas. Los gobiernos les van retirando su apoyo a medida que se des- 
moronan los imperios coloniales, lo que vino a coincidir con el progresivo abandono de los esquemas evolucionistas y difusionistas, a favor de un funcionalismo que en nada se adecúa a las viejas clasificaciones museológicas. Pero los nuevos planteamientos antropológicos no trajeron como consecuencia replanteamientos en la museología etnológica. El presentismo, con su desinterés por el estudio de los procesos de cambio cultural, provoca que los museos sigan llenándose de los más variopintos objetos, inservibles para un análisis científico intercultural.

No obstante, todavía asistiremos a la creación de algunos de estos museos, como el Musée des Colonies en París, inaugurado en 1931, que "tenía por misión principal servir de medio de educación e incluso de propaganda, con el fin de alentar a los jóvenes a iniciar una carrera o una actividad que los condujera a ejercer en esos territorios y a contribuir a difundir allí el mensaje de la metrópolis" 7 .

Por el contrario, los museos etnográficos van multiplicándose, reduciendo progresivamente su campo de interés a entidades geográficas menores. Cada pequeña localidad parece querer demostrar su singularidad a través de la exposición de los restos de su pasado.

España se ha sumado a esta inercia con bastante retraso. Los años del franquismo no fueron los más propensos para resaltar individualidades culturales. Muy al contrario, se fomentó la tendencia colonialista, con ejemplos tan reveladores como la creación del Museo de América en Madrid, en 1941, con el fin de

"patentizar la gesta del descubrimiento y estudiar las culturas indígenas, el arte colonial y la obra misional, de los cronistas y los jurisconsultos"8.

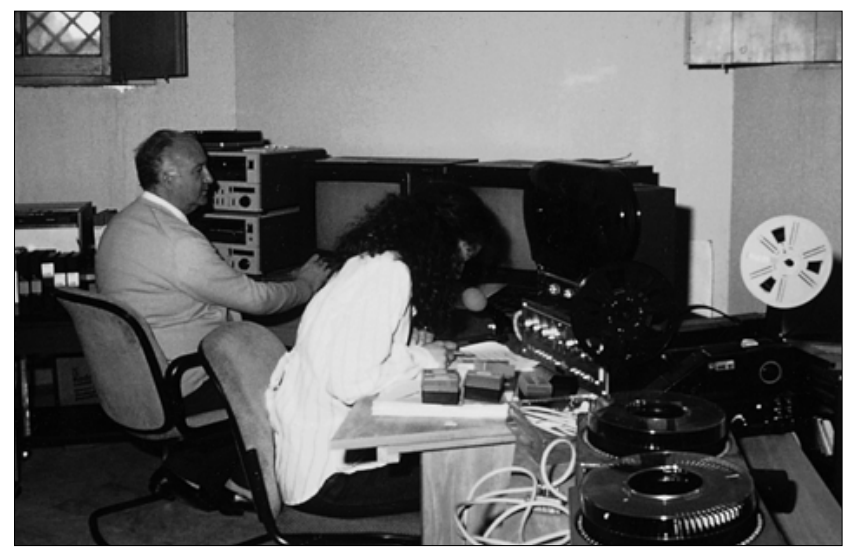

4. Laboratorio de audiovisuales nas. En él se incluye como Sección Hispánica, en 1962, el Museo de Industrias y Artes Populares (creado en 1940), quizá para diluir la concepción de lo propio e incrementar la visión triunfalista de la historia del gran Estado Español y sus colonias?.

Con todo, el gobierno de aquellos años no ignoraba que unos museos que exhibieran objetos tradicionales, extraídos del pasado rural, conllevaban una innegable rentabilidad turística y emprende, dentro del II Plan de Desarrollo, una política de creación de museos de artes y costumbres populares. Así, mientras el Museo del Pueblo Español seguía cerrado, se redactan proyectos como el que sigue:

"La defensa y conservación de los valores del pasado, en su condición de peldaños que permitieron alcanzar las conquistas del presente, obliga a considerar con harto justificada preocupación la grave amenaza de desaparición de aquellos exponentes de los valores populares que representan la esencia del ambiente, el carácter y el desarrollo, de la vida en todo el ámbito nacional, pues una parte importante de esta representación vital de España va perdiéndose en las ondas del olvido y tras los afanes incontenibles de la renovación"I0.

El impulso definitivo llegará con el establecimiento de la España de las Autonomías. Entonces parece quererse recuperar el tiempo perdido a la mayor celeridad y comienzan a proliferar, con asombrosa rapidez, museos y colecciones etnográficas a lo largo y ancho de nuestra geografía. Las más de las veces continúa prevaleciendo el más puro estilo romántico decimonónico, ante los ojos imperturbables y desinteresados de una alarmante mayoría de antropólogos, constituidos ya como colectivo profesional.

\section{Conceptos MUSEOLógicos}

En esos momentos, mucho se había avanzado en teoría museológica. Los distintos organismos internacionales dependientes de la UNESCO discutían y legislaban sobre conceptos tales como patrimonio, bien cultural y, por supuesto, museos como depositarios de muchos de esos bienes culturales que conforman el patrimonio de cada grupo cultural. Se suceden los encuentros, recomendaciones, normativas y publicaciones especializadas, que difunden nuevos planteamientos teóricos y metodológicos. El camino para la superación de los viejos esquemas está abierto.

En este contexto, España entiende la necesidad de una nueva ley de Patrimonio que actualice sus contenidos y la proclama en 1985. A partir de ella se suceden distintas leyes y reglamentos, como consecuencia de la nueva distribución de competencias que, en este campo, se reparten el Estado y las Comunidades

Autónomas.

Semejante finalidad debió de perseguir la apertura en Barcelona, siete años después, del Museo Etnológico, con colecciones especialmente referidas al imperialismo español: Hispanoamérica, Norte de África y Filipi-

A pesar de la especificidad geográfica de sus colecciones, acuñadas tras siglos de coleccionismo americanista, el Museo expuso también objetos de otras antiguas colonias oceánicas y africanas.

En todas ellas aparece al fin contemplado el Patrimonio Etnológico. Por primera vez se admite que unos bienes que no son ni antiguos ni bellos ni únicos, merecen idén- 
ticas medidas de protección y fomento que los restos arqueológicos, los monumentos arquitectónicos o las obras de los grandes artistas. Y no sólo eso, sino que además deberán protegerse los conocimientos y las actividades propios de un determinado grupo cultural " .

Indiscutiblemente el avance es notorio, aunque en la práctica se continúe considerando como un patrimonio menor y haya que seguir justificando día a día la necesidad de proteger un viejo molino de rodezno, el instrumental de un zapatero remendón o los toques de los verdiales. Y no parece disparatado presagiar que esta realidad tiene visos de continuar largo tiempo.

Los antropólogos son los profesionales capacitados para hacer comprender que todo ello son documentos esenciales para entender nuestro presente cultural. Y de momento somos pocos y con poca fuerza, en comparación con otros colectivos. Pero además, no siempre todas las voces entonan la misma copla. Siempre hay quien, aun admitiendo la incuestionabilidad del argumento, no se resiste a establecer una escala valorativa entre los aspectos de la cultura al parecer más dignos de estudio y protección y lo más accesorio, campo éste en el que siempre cae la mal llamada e infravalorada "cultura material". Precisamente esas cosas de las que se ocupan los museos.

Para razonar la inadecuación de este término, siempre remito a las palabras de Limón Delgado:

"[...]《cultura material» es un concepto redundante porque no hay fenómenos culturales que no participen de este concepto de materialidad perceptible que lleva implícito su carácter de fenómenos. [...] Cuando se trata de observar una creencia religiosa, la imagen que inconscientemente se forma de ella el investigador es la de algo que la gente «tiene en su cabeza», que le hace creer esto o aquello; pero de hecho, si tal creencia religiosa no se materializara virtualmente en algún tipo de conducta externa (poner una vela, arrodillarse para rezar, visitar un lugar sagrado, etc.) mal podría llegar a ser observada y por tanto nunca tendría el carácter de fenómeno observable. En todo caso, esa creencia podría ser legítimamente objeto de observación introspectiva para el mismo sujeto que la posee, pero esta salvedad es de escasa utilidad para el observador convertido en etnógrafo."I2.

Sólo entendiendo que el distingo entre material e inmaterial, cuando a estudio de la cultura se refiere, no es más que un recurso metodológico para abordar su análisis, podemos empezar a aceptar el carácter de documento cultural que conllevan todas las piezas museables. Son las velas y también los exvotos los que nos hablan del mecanicismo de la religiosidad popular, en su intercambio de favores con la divinidad; es el paso procesional, con su manto y sus joyas, el que atestigua el sentido teatral de su expresión. A través de la vestimenta puede explicarse la organización social, al revelar las distinciones de género, edad, cargo, ocupación, clase social. Analizando los juguetes estamos estudiando mecanismos de enculturación, modos de transmitir valores y pautas de comportamiento a los nuevos miembros de la sociedad. Útiles de cestería o de cerámica pueden evidenciar una economía de autoabastecimiento, a la vez que testimonian las técnicas específicas con las que un grupo humano ha dado respuesta a una necesidad; lo mismo que unas labores de encaje, que además nos están informando de roles laborales.

En suma, un museo etnográfico es (debe ser) un centro que custodia bienes culturales de nuestro patrimonio, no para llorar su pérdida ni para enarbolar banderas etnocéntricas sino para enseñar cultura. Tarea de la que, evidentemente, sólo deberían encargarse los profesionales de la cultura, al igual que en cualquier otro centro docente.

Lo contrario es seguir considerando al objeto como el fin y no como el medio, cuando la finalidad de conservar y custodiar unos bienes patrimoniales no puede
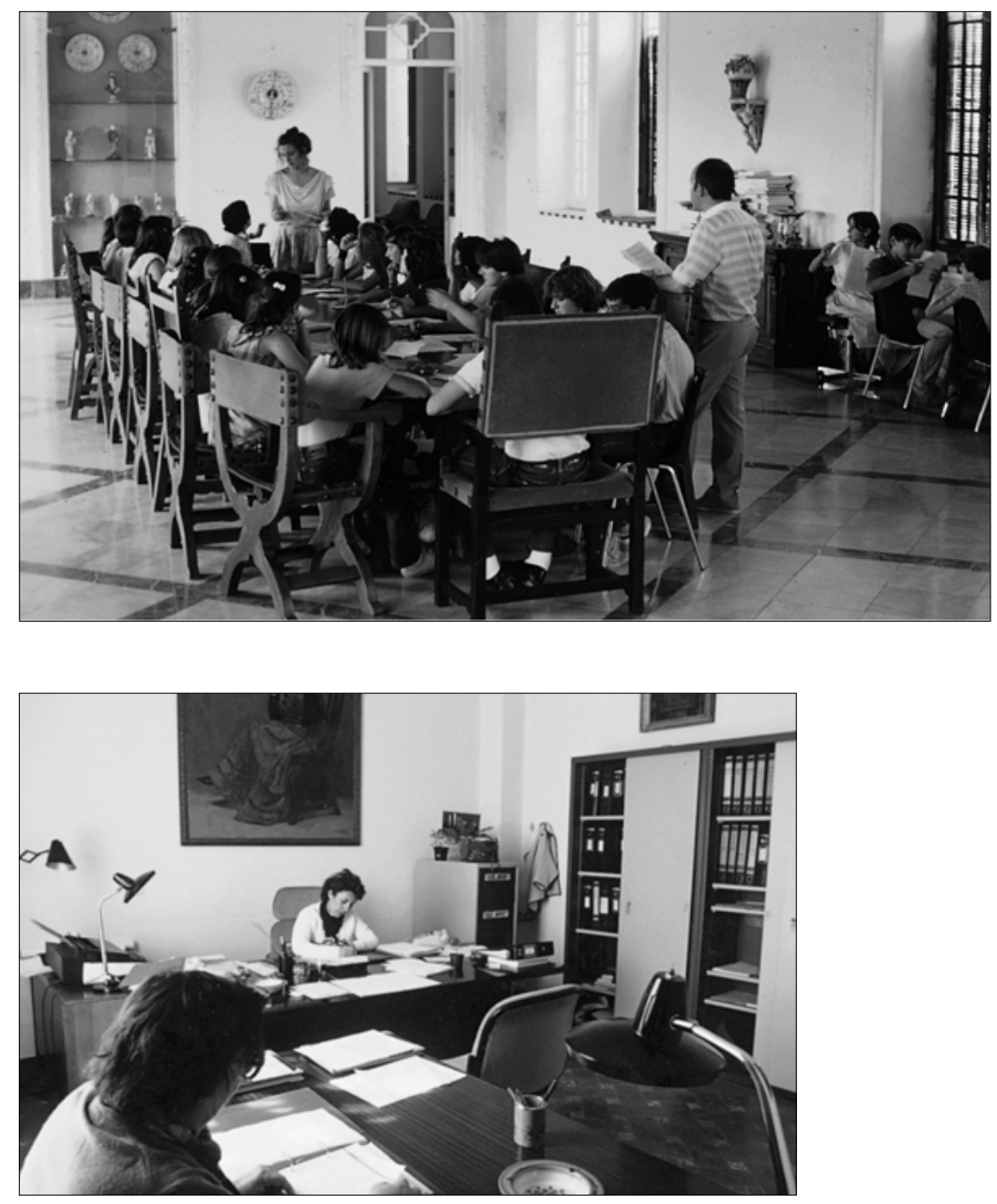

5. Salón de lectura y actividades

ser otra que la de que todos podamos comprender 6. Despacho de administración nuestra propia identidad y aprender el respeto a las identidades ajenas.

Ese mismo culto al objeto es el que ha llevado a suponer, de modo bastante ingenuo, que ellos tienen por sí mismos la capacidad de transmitir todo su significado cultural. Basta con colocar en una serie de vitrinas - del modo más estético posible- las velas, los exvo- 
tos, los trajes, los juguetes, la cerámica, etc., para que el público que los observa aprehenda todo su significado. Cuando esto se hace así, el único mensaje que llega a la gran mayoría de visitantes es esa mezcla de curiosidad y nostalgia por los objetos de un pasado no demasiado lejano: conforman su historia, pero nada tienen ya en común con su presente cultural.

Bajo esa carencia de teoría museológica se explica, además, la multiplicación de los autodenominados museos etnográficos en cualquier localidad que haya conseguido recolectar una serie de objetos en desuso y haya encontrado un local donde mostrarlos. Independientemente de la buena intención de sus artífices y del reconocimiento que merecen por la labor de sal-

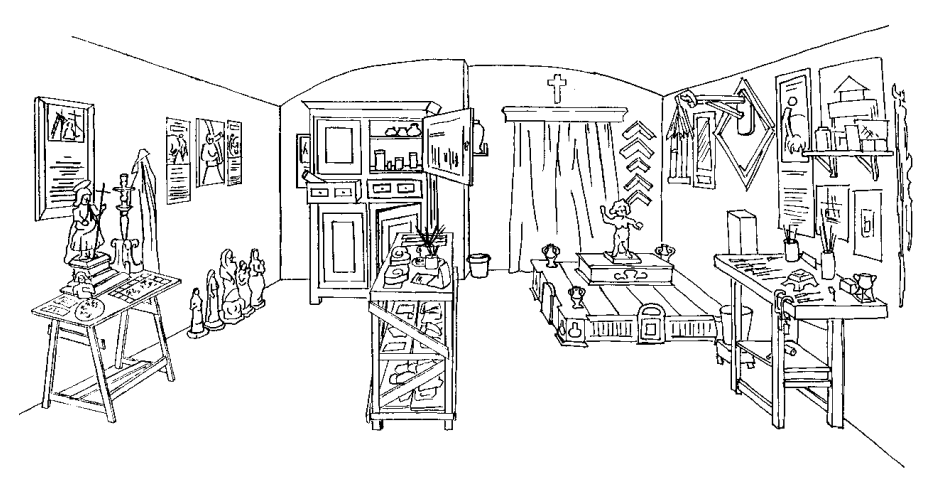

I. Taller de dorado

vaguarda de determinadas piezas, esos lugares jamás deberían ser bautizados como "museos etnográficos", porque no son ni lo uno ni lo otro.

Atendiendo a la definición del ICOM, hoy no puede considerarse museo a ningún centro que no atienda al desarrollo de las funciones a ellos encomendadas: adquisición, conservación, catalogación, restauración, exhibición, investigación y divulgación de una parte del patrimonio cultural' ${ }^{3}$. Esto requiere una infraestructura que comprenda almacenes adecuadamente equipados, instrumentos de documentación y catalogación, talleres de restauración, laboratorio fotográfico, biblioteca especializada, gestión administrativa, sala de exposiciones temporales, etc. Todo ello con el objetivo final de servir de instrumento a la interpretación cultural.

Por su parte, el adjetivo etnográfico sólo puede ser aplicable cuando es la ciencia antropológica la que sirve de marco teórico a dicha interpretación. De ahí la responsabilidad de los profesionales que dejan en manos ajenas una labor de divulgación que sólo a ellos compete y que llega, además, a todo tipo de público.

\section{Procedimientos museográficos}

Entre los primeros antropólogos conscientes de la capacidad educativa de los museos se encuentra el francés Rivière, quien, junto a Rivet, protagonizará en los años treinta la remodelación del Musée de
I'Homme y la creación del Musée des Arts et Traditions Populaires, a la vez que promovió intensamente la formación de ecomuseos. Ejemplos todos que han llegado a convertirse en claros referentes para la museografía etnográfica española, en sus variadas manifestaciones.

La interpretación de la cultura a través de los objetos seleccionados para una exposición, puede plantearse de muy diversas maneras. Obviamente no recibirá idéntico tratamiento un museo que persiga revelar las formas plurales de la cultura, que otro encaminado a la transmisión de la propia identidad, o aquéllos que se centran monográficamente en un único aspecto de la misma.

Del primer caso, el proyecto más ambioso en España es el del Museo Nacional de Antropología, que, como sabemos, reunirá las colecciones procedentes de los antiguos Museo del Pueblo Español y Museo Nacional de Etnología. De este modo, el patrimonio de los distintos pueblos de España pasará a ser estudiado como un integrante más de las formas culturales de la humanidad. Tal como explica Carretero Pérez:

"La finalidad básica de la muestra, el hilo conductor que guíe al visitante, y que articule la narración, ha de ser la complejidad de la estructura cultural, y la continua evolución o cambio de las prácticas; el contraste entre permanencia y cambio, entre unidad y diversidad cultural; la explicación de que 'todo tiene una fecha' y un contexto" 14 .

La aproximación inicial apuntada para la exposición comenzaría con un área introductoria donde "se expliquen los conceptos básicos de la mecánica cultural y de la disciplina antropológica", seguida de las salas que van mostrando la diversidad cultural, sea a través de áreas geográfico-culturales o bien considerando los elementos culturales al margen de su distribución espacial. Cualquiera que sea la opción final elegida, de lo que no cabe duda es de la contribución que un museo, así planteado, puede hacer a la extensión del relativismo cultural o, lo que es igual, a la disminución del etnocentrismo, del racismo y de la incomprensión entre las culturas.

Otro de los museos magníficamente replanteados en los últimos años (1994) es el Museo de América, quien igualmente estudió la disyuntiva entre una ordenación expositiva que recorriera las diferentes áreas geográfico-culturales americanas o que fuera analizando áreas temáticas. Aprobado este camino, el siguiente paso fue seleccionar los temas con los que mostrar la realidad cultural del continente, determinándose los siguientes: los instrumentos del conocimiento, la realidad americana, la sociedad, la religión y la comunicación. A través de ellos, el público va adentrándose en el conocimiento de los rasgos culturales tanto precolombinos como coloniales, percibiendo el valor singular de los distintos aportes que conforman la América actual.

Como recursos museográficos cabe destacar la utilización de vídeos, de corta duración, que introdu- 
cen cada uno de los temas abordados. Asimismo se emplean maquetas, gráficos y mapas, entre los que sobresale el que inicia La realidad americana, que se presenta acompañado de un interesante montaje audiovisual.

Cuando, por el contrario, el museo se centra en el patrimonio cultural propio, (los que hasta ahora venimos denominando "etnográficos" o de "artes y costumbres populares"), lo más frecuente en España es encontrarlos como una pequeña sección independiente en el interior de los museos provinciales. Y si ello es un claro reflejo de las distintas trayectorias académicas y profesionales seguidas en nuestro país por la Arqueología, las Bellas Artes y la Antropología, hoy no parece tener sentido la continuidad de esta disparidad museológica.

Por aportar algunos datos, de los 31 museos andaluces integrantes del Sistema Español de Museos, sólo 4 son de Artes y Costumbres Populares (Sevilla, Granada, Cazorla y Jaén), a los que hay que añadir la sección etnográfica del Museo de Cádiz. El resto de los museos provinciales, o no la han contemplado nunca, o están terminando siendo relegadas. Entre los de titularidad privada, cabe mencionar el Museo de Artes y Tradiciones Populares de Málaga, que en 1973 se hizo cargo de la pequeña colección etnográfica existente en los almacenes del Museo Provincial, completándola con una gran campaña de recolección de fondos por toda la provincia.

El programa expositivo ideado en los años sesenta por Lévi-Strauss y Rivière para el ATP francés, es el que ha servido de guía, en una gran medida, a la presentación de las exposiciones de estos museos. Al estar referidos a una específica área cultural, la exposición suele distribuirse en base a grupos temáticos con los que ejemplificar la dinámica de las formas de vida estudiadas. Pero si en un museo de nueva creación puede plantearse una recogida metódica atendiendo a los criterios de selección programados, lo más frecuente es encontrarse con una herencia de fondos que en parte determina la composición del montaje final, en la búsqueda de su coherencia expositiva.

De cualquier forma, la estructuración suele atender a los grandes bloques metodológicos con los que se aborda el estudio de la cultura: la relación del hombre con el medio, con sus semejantes y con las dimensiones cognitiva y sobrenatural. En el primero se incluirán las técnicas de producción, transformación y consumo, el hábitat, los transportes, etc.; en el segundo las relaciones familiares, la enculturación, el ciclo vital, la estratificación social, el asociacionismo, etc.; y en el tercero, los valores, las creencias, la religiosidad popular, las fiestas, las manifestaciones artísticas, etc.

Esta articulación no impide que la exposición atienda otras ordenaciones con las que ahondar en determinados aspectos culturales. El Museo de Artes y Costumbres Populares de Sevilla, por ejemplo, dise- ñó una serie de salas atendiendo al aspecto funcional de los objetos, mostrando las funciones del mobiliario o del ajuar domésticos, o los usos de la cerámica popular. También hallamos repertorios descriptivos en los tipos de contenedores domésticos, o en las técnicas de azulejería o de bordados y encajes. Asimismo analiza variedades locales, como las de la producción alfarera andaluza.

Otro recurso museográfico empleado por este Museo es el de la recreación de ambientes, tanto de talleres de oficios artesanos como de habitaciones domésticas. El
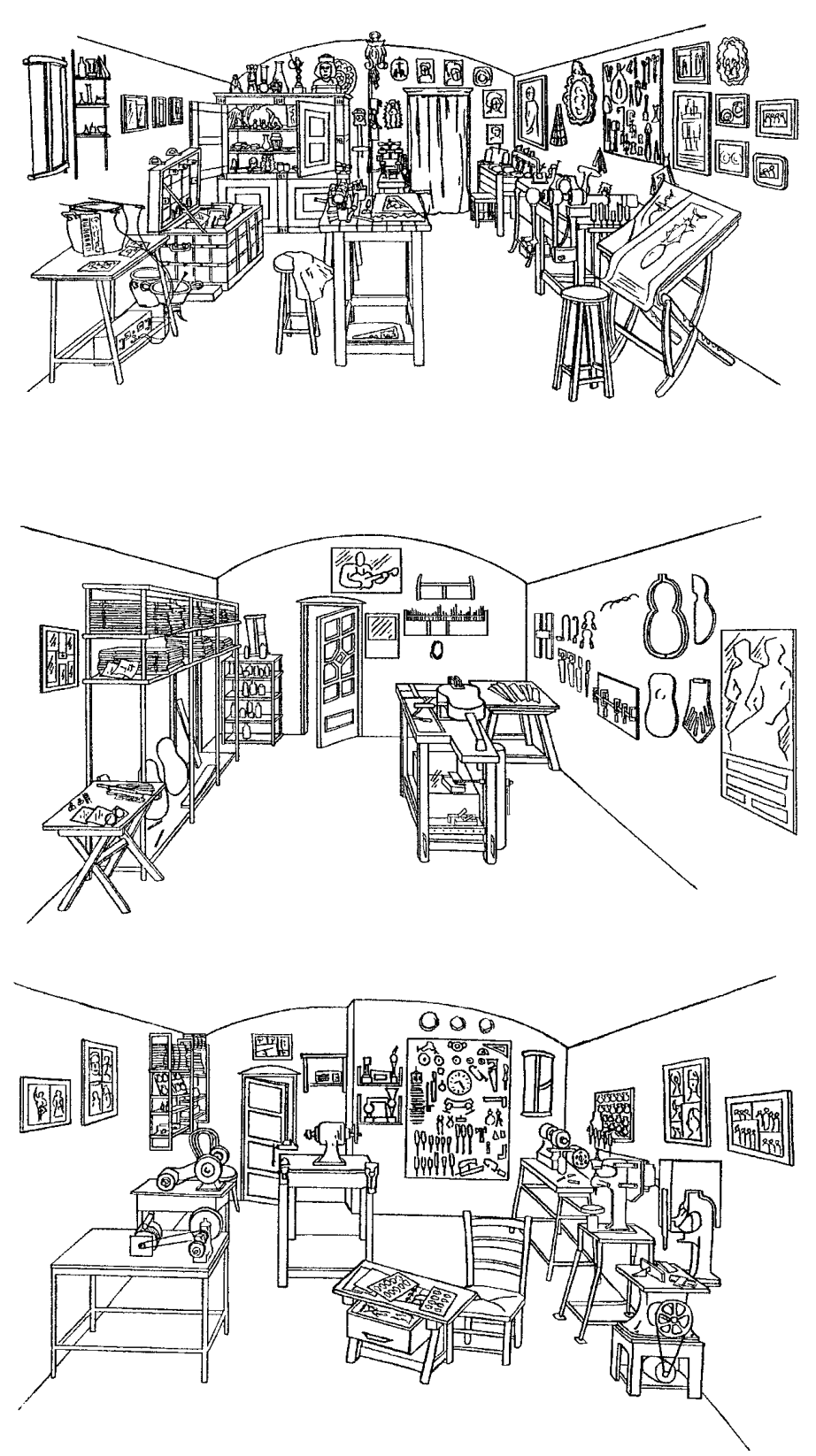

2. Taller de orfebrería

interés de éstas últimas radica, además, en el enfrentamiento espacial de las estancias correspondientes a un hogar de trabajadores agrícolas con las de una vivienda de la burguesía urbana, mostrando gráficamente el contraste entre los modos de vida en niveles sociales dife-
3. Taller de guitarras

4. Taller de palillos 
rentes. Idéntica finalidad ha guiado la reconstrucción íntegra de la casa-taller de unas bordadoras sevillanas, ejemplo de la concepción estética y funcional de una determinada clase social.

Igualmente se utiliza el material audiovisual como apoyo y complemento de la exposición, recogiendo imágenes en su propio contexto, que añaden una información precisa y fehaciente sobre la continuidad o el cambio de determinadas prácticas culturales.

El otro modo de presentación, el de los museos al aire libre, no ha conseguido arraigo en España al igual que en la mayoría de países del sur de Europa. No obstante, en los años en que Caro Baroja ocupó la dirección del inconcluso Museo del Pueblo Español, proyectó para él una instalación al aire libre en terrenos de la Casa de Campo o bien en la Ciudad Universitaria.

Sí llegó a crearse, en 1968, el Museo de la Huerta de Murcia, a propuesta del ayuntamiento de Alcantarilla. La idea original consistía en plasmar la forma de vida tradicional del labriego, construyendo una serie de barracas tradicionales en torno a una secular rueda de riego que se conserva junto a su acueducto, no lejos de una aceña que también sería visitable. A ello
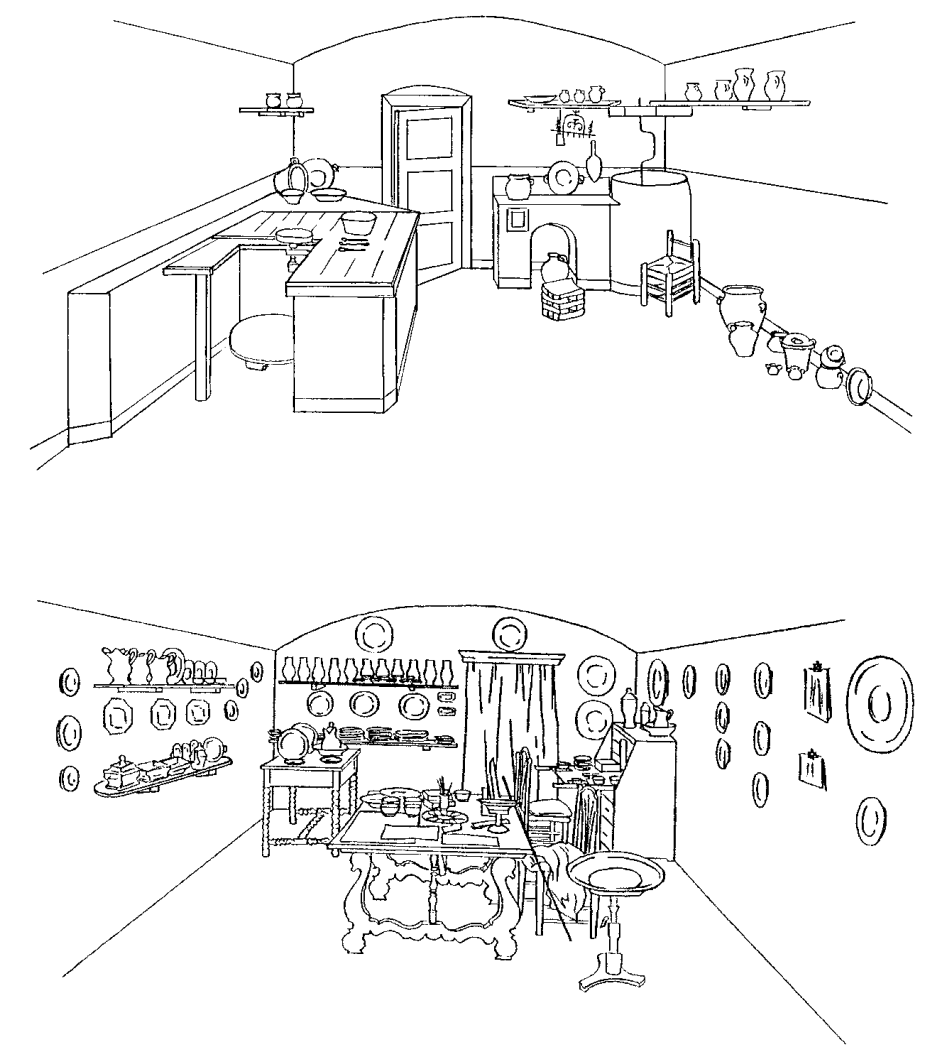

5. Taller de cerámica

6. Taller de pintura de loza

se sumó la realización de un monumento al huertano. Sin embargo, la exposición de los objetos con que se quiere mostrar esta cultura se presenta finalmente en un edificio destinado a museo, con su tradicional distribución en salas.
Concepción distinta es la de los ecomuseos, de los que tampoco contamos con demasiados ejemplos. En este caso no se trata de edificar las construcciones tradicionales para recrear su uso, sino de mantener los espacios tal como existieron en realidad y a sus gentes desarrollando las actividades que han llegado a configurar su identidad. De esta manera se logra que una comunidad salvaguarde toda una serie de prácticas y conocimientos, junto a los bienes muebles e inmuebles de su patrimonio, que se convierte así, además, en un activo motor de desarrollo local.

Un modelo en España de esta concepción museológica es el reciente Parque Etnográfico do Río Arnoia en Allariz (Ourense).

"Es una propuesta en marcha que incluye el saneamiento y recuperación de las márgenes del río Arnoia implicando en este programa la restauración y rehabilitación de una serie de establecimientos industriales ligados a las actividades realizadas tradicionalmente con el concurso y aprovechamiento de la energía hidráulica" 15 .

Estos establecimientos están referidos principalmente a molinos y curtidurías, que fueron abandonando progresivamente su actividad. El proyecto emprendido ha supuesto la recuperación de varios de ellos: unos para reconstruir los procesos de trabajo y otros para su reutilización como servicios para el turismo rural, pero todos manteniendo sus elementos originales. Así, en una de las curtidurías destinada a Museo do Coiro, un artesano sigue trabajando y vendiendo sus productos; otra edificación se ha convertido en el Museo do Tecido, donde también se mantiene y se enseña las labores de hilado y tejido.

Como vemos, no existe una única forma para la museografía etnográfica aunque, en suma, todos ellos buscan mostrar la unidad y a la vez diversidad de las respuestas culturales, en distintos medios y distintas épocas, analizando su dinámica a través del patrimonio que identifica a sus miembros.

\section{Campo de trabajo}

Esta comunicación no se establece a través de la palabra o la letra impresa sino a través de los objetos, y, evidentemente, dominar el lenguaje visual no es algo que pueda improvisarse. La Antropología, como otras ciencias, tendría que contemplar este aspecto en la formación de sus futuros profesionales, y no como enseñanza meramente teórica sino con el apoyo de verdaderas prácticas museológicas ${ }^{16}$.

Ya Lévi-Strauss preconizaba hace muchos años el "papel del museo de antropología como prolongación del campo de trabajo" I7, tal como venía haciéndose en el Musée de l'Homme, sede del Instituto de Etnología de la universidad de París desde 1925. De hecho, las primeras cátedras de Antropología estuvieron siempre instaladas en los museos de Historia Natural, incluida en España la del primitivo Museo 
Antropológico; el mismo que mucho después, convertido en Museo Etnólogico Nacional, acogió la Escuela de Estudios Antropológicos bajo la dirección de Esteva Fabregat, donde se formaron no pocos de los actuales profesionales de la disciplina ${ }^{18}$.

La inclusión de la asignatura Patrimonio Etnológico y Museología en la nueva licenciatura de Antropogía, puede suponer sin duda un pequeño paso en este camino. Los estudiantes de la Univesidad de Sevilla han tenido ya ocasión de comprobar el abismo muchas veces existente entre las teorías museólogicas y su aplicación práctica 19. Los nuevos conceptos de museo no siempre van acompañados de realidades inmediatas, al tropezar todavía en la actualidad con dificultades de diversa índole: insuficiente dotación de personal especializado para cumplir adecuadamente las funciones encomendadas, herencia de unas colecciones conformadas por piezas que fueron recogidas sin criterios museográficos, escasos presupuestos y excesiva rigidez administrativa para su gestión; y muchos más, entre los que no cabe olvidar la inalteración de arcáicos planteamientos en buen número de profesionales relacionados directa o indirectamente con la marcha de estas instalaciones.

Para los museos de Antropología en concreto, éste último inconveniente sólo podrá remontarse si los antropólogos toman conciencia de él. Y analizar críticamente el desarrollo histórico de estas instituciones es el único modo de comprender su realidad presente, de igual manera que estudiar la historia de las corrientes de pensamiento antropológico es el camino empleado para adentrarse en la comprensión de su teoría y métodos actuales.

"Ahora bien, una de las paradojas -y no es de las menores- de las investigaciones realizadas en historia de la etnología es el no haber tenido en cuenta ese ostensible aspecto público e incluso espectacular de la disciplina en donde tanto la alteridad como el exotismo estaban al alcance de los ojos, convirtiéndose en un bien común visiblemente compatible sin distinción de raza ni de clase, y en donde, en sentido estricto, la etnología se ponía a representar su papel, colocando en escena y con sentido sus objetos preferidos. Debido a su forma por lo general monumental, a su posición central en el aparato cultural de la ciudad, a su función que hoy en día se llamaría mediática, y también con toda seguridad a su objetivo que era (y aún es
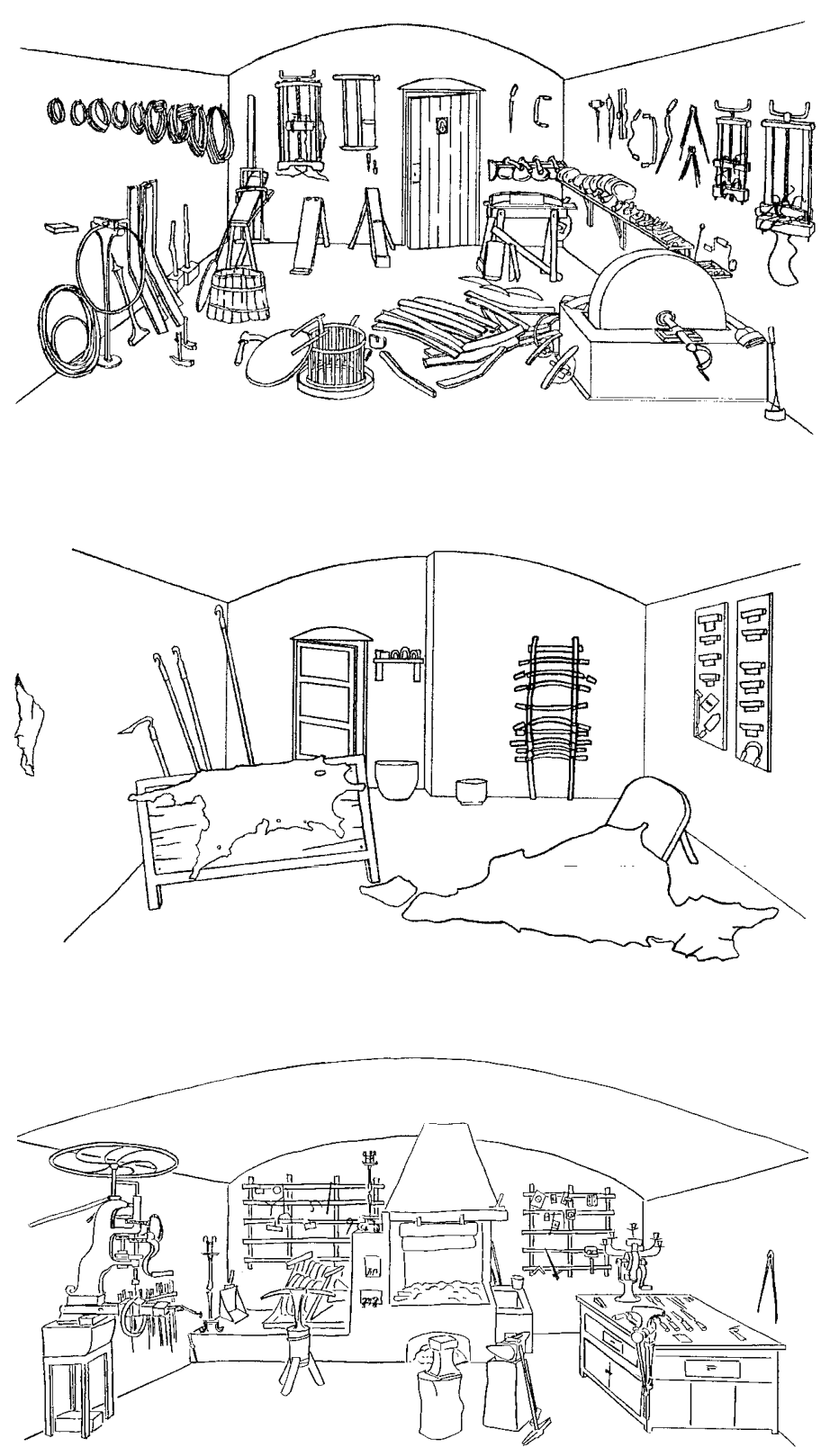

hoy todavía) el de mostrar o mejor, en el sentido literal de la palabra, exponer los signos materiales de las otras culturas, los museos de etnografía o de antropología han podido jugar un activo papel en la transformación o incluso en la elaboración de las representaciones de la alteridad cultural" 20.

\section{Fotografías}

Archivo del Museo de Artes y Costumbres Populares de Sevilla. Autor: Mario Fuentes Aguilar

\section{Dibujos Talleres}


I. Entendiendo como tales a los que la Historia de la Antropología reconoce como sus primeros representantes, aun encontrándonos muy lejos de la institucionalización de la profesión.

2. Una descripción detallada de estas exposiciones puede encontrarse en ROMERO DE TEJADA, P.: "Exposiciones y museos etnográficos en la España del siglo XIX" en Anales del Museo Nacional de Antropología, II: I I-47. Madrid, 1995.

3. PRATS, L:: "El estudio y la gestión del patrimonio etnológico en España. El caso de Cataluña" en El Patrimonio Etnológico: 152. Santa Cruz de Tenerife, 1993.

4. Ver ORTIZ GARCIA, C.: Luis de Hoyos Sáinz y la Antropología española. Madrid, 1987.

5. Decreto Fundacional del Museo del Pueblo Español, de 26 de julio de 1934. Recogido en Anales del Museo del Pueblo Español, I: 5- |0. Madrid, 1935. Le sigue el Reglamento de Aplicación, los nombramientos correspondientes, las actas de constitución del Museo, el Comité Ejecutivo y el Patronato, y la Circular General y Cuestionario para la recogida de objetos.

6. Un resumen de los avatares de este Museo puede verse en BERGES SORIANO, P.M.: "Museo del Pueblo Español" en Anales del Museo Nacional de Antropología, III: 65-88. Madrid, 1996.

7. KLEIBER-SCHWARTZ, L.: "De museo de las Colonias a Museo de las Comunidades" en Museum, 175: 137. París, 1992.

8. CABELLO, P.: "El Museo de América" en Anales del Museo de América, 1: 17. Madrid, 1993.
9. No será hasta 1982 cuando vuelva a independizarse de manos del gobierno autonómico, ahora bajo la denominación de Museu d'Arts, Indústries i Tradicions Populars.

10. CHAMOSO LAMAS, M.: "La creación de museos de Artes y Tradiciones Populares en Galicia" en Actas del II Congreso Nacional de Artes y Tradiciones Populares: 34. Zaragoza, 1974

II. Sobre el patrimonio inmaterial ver RIOJA LÓPEZ, C.: "Reflexiones en torno a la cultura inmaterial y su gestión patrimonial en la Comunidad Autónoma Andaluza" en Boletín del Instituto Andaluz de Patrimonio Histórico, 16: 79-84. Sevilla, 1996

12. "Sobre el método" en Anales del Museo del Pueblo Español, II: 70. Madrid, 1988.

13. Una profunda reflexión a la definición oficial de museos puede verse en LIMÓN DELGADO, A.: "La educación y museos (I)" en Boletín Informativo del Colegio Oficial de Doctores y Licenciados en Bellas Artes y Profesores de Dibujo Andalucía, 3: 4-5. Sevilla, 1993.

14. "El Museo Nacional de Antropología: Nos/Otros" en Anales del Museo Nacional de Antropología, I: 230. Madrid, 1994.

15. SIERRA RODRÍGUEZ, X.C.: "El «Parque Etnográfico do Río Arnoia», Allariz" en Revista de Museología, 5: 63. Madrid, 1995.

16. Para profundizar en las posibles soluciones al problema actual de la formación de museólogos ver "Formación y selección de Profesionales de Museos" Museo, I. Madrid,

\section{LAS JORNADAS Y EL ANUARIO ETNOLÓGICO DE ANDALUCÍA}

La Consejería de Cultura, a través de su Dirección General de Bienes Culturales, viene celebrando desde 1990, con carácter anual, las Jornadas de Etnología Andaluza, como foro de exposición y debate de los resultados alcanzados en la investigación de los Planes Anuales de Etnología. Hasta la fecha se han celebrado siete Jornadas en las localidades de Sevilla, Córdoba, Málaga, Jaén, Cádiz, Almería y Huelva, respectivamente.

Además de las Jornadas, los trabajos frutos de los Planes Anuales de Investigación se vienen publicando por parte de la Consejería de Cultura en los Anuarios Etnológicos de Andalucía. Hasta la fecha se han publicado cuatro Anuarios que reúnen los trabajos de investigación de los años 1989-90, 1991, 1992-93 y 1994.

\section{Información:}

Consejería de Cultura de la Junta de Andalucía Dirección General de Bienes Culturales Servicio de Investigación y Difusión

C/ Levíes 17

41004 Sevilla

Teléf:: 95/ $4559860 \quad$ Fax: 95/4559865 